\title{
Is it Nephroscopy or Pseudocyst-Scopy?
}

\author{
Pankaj N. Maheshwari ${ }^{1}$
}

Received: 1 August 2021 / Accepted: 7 August 2021 / Published online: 12 August 2021

(c) Association of Surgeons of India 2021

Sir,

I read this interesting surgical technique by Lu B et al. regarding the nephroscopic management of the giant infected pancreatic pseudocyst [1]. I compliment the authors for this very innovative technique, but I have very basic comments regarding this manuscript.

The title of the manuscript is misleading and probably wrong. The technique cannot be called as nephroscopy, as nephroscopy means looking inside a kidney by a telescope. Nephroscopy is an endoscopic technique for evaluation and management of calculi or other lesions inside the kidney [2]. What was done in the above-mentioned technique was pseudocyst-scopy. Yes, nephroscope and the dilatation techniques that are routinely used for a standard per-cutaneous nephroscopy were used here, but the procedure would be called as a "pseudocyst-scopy using a nephroscope" and not nephroscopy.

Author Contribution Single author.
Availability of Data and Material Not applicable.

\section{Declarations}

Ethics Approval Not applicable.

Consent to Participate Not applicable.

Consent for Publication Not applicable.

Conflicts of interest None.

\section{References}

1. Lu B, Jia Z, Li S, Cai Y, Yin J, Wang J (2021) Nephroscopic management of giant infected pancreatic pseudocyst after drainage. Indian J Surg 83:754-757. https://doi.org/10.1007/ s12262-020-02483-6

2. Tran TY, Gupta M (2019) Rigid and flexible nephroscopy. Smith's textbook of endourology, 4th edn. Wiley Blackwell, Oxford, pp 285-293

Publisher's Note Springer Nature remains neutral with regard to jurisdictional claims in published maps and institutional affiliations.

Pankaj N. Maheshwari

dr.maheshwaripn@gmail.com

1 Division of Endourology, Fortis Hospital Mulund, Mulund-Goregoan Link Road, Mulund-West,

Mumbai 400078, India 